\title{
CONSTRUCTION OF LOOP FABRICS
}

\section{J. H. Quilter}

To cite this article: J. H. Quilter (1912) CONSTRUCTION OF LOOP FABRICS, Journal of the Textile Institute Proceedings and Abstracts, 3:2, 276-293, DOI: 10.1080/00405001208631728

To link to this article: http://dx.doi.org/10.1080/00405001208631728

$$
\text { 曲 Published online: } 01 \text { Dec } 2008 .
$$

Submit your article to this journal

Џll Article views: 4

Q View related articles ¿ 


\title{
CONSTRUCTION OF LOOP FABRICS.
}

\author{
By J. H. Quilter (Leicester).
}

IT is not my intention in this paper to deal with the subject of the manufacture of looped fabrics, but rather to attempt to show briefly the different structural characteristics of such fabrics as are manufactured by mechanical means, and which have been so instrumental in bringing the knitting industry to its present position as a serious rival to other textile industries.

The mechanical construction of a looped fabric dates back to the time of the invention of the first stocking frame in 1589 , when William Lee, by the introduction of his frame, made it possible to knit a whole row of loops during a series of movements, as against the earlier method of forming each loop singly by hand. Each row of these loops was formed from a single thread on a number of needles equal to the number of loops being made in each row, such loops being formed in a similar direction, with each row of loops as completed supporting a similar row, the continuation of such rows building up a fabric. This principle of knitting from a single thread continued until the year I 775 , when a looped fabric was introduced which was made from a number of threads equal to the number of needles employed in the width of the fabric. In this frame, or loom, as it was called, each thread formed a loop over one needle only, the loops of each row being united by each thread having a side-way connection with the adjoining thread. In this fabric, the threads used therefore formed loops lengthways of the fabric instead of crosswise, as in the original method.

These two principles form the basis upon which all present-day looped fabrics are constructed, and this being so, looped fabrics may be divided into two distinct classes:-

First: Those fabrics made from horizontally knitted threads (or wefts).

Second: Those made from vertically knitted threads (or warps).

I introduce these terms "warps" and "wefts," they being better understood by those who are more closely acquainted with the construction of woven fabrics in which warp and weft threads are used. In the knitting industry, however, these fabrics are technically distinguished as "framework-knitted fabrics" and "warp-knitted fabrics," and it is under these headings that I propose to deal with each separately, taking first the older principle of : - 
FRAMEWORK-KNITTED (OR Weft) FABRics,

In the construction of this class of fabrics there are three distinct arrangements of the loops known as:-

Plain Knitting (Class " A").-In this fabric the whole row of the loops has one uniform construction, each loop lying in a

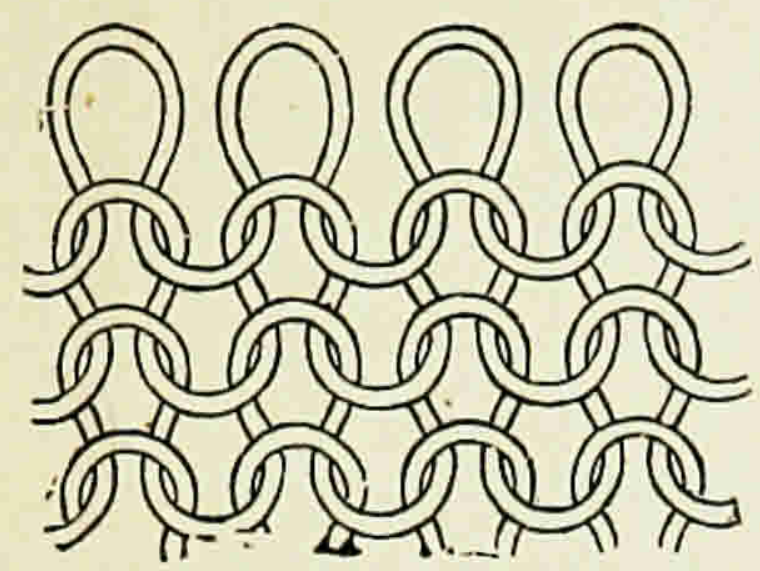

similar direction. It is made on a single set of needles, and the finished fabric has a different appearance on each side.

Ribbed Knitting (Class " B").-In a ribbed fabric the loops of each row are formed in two directions, some lying to the face of the fabric and others to the back. This necessitates the use of two sets of needles or special needles, the loops being formed reversely, so according to the arrangement of the needles different styles of ribbed fabrics can be made, the simplest form being that

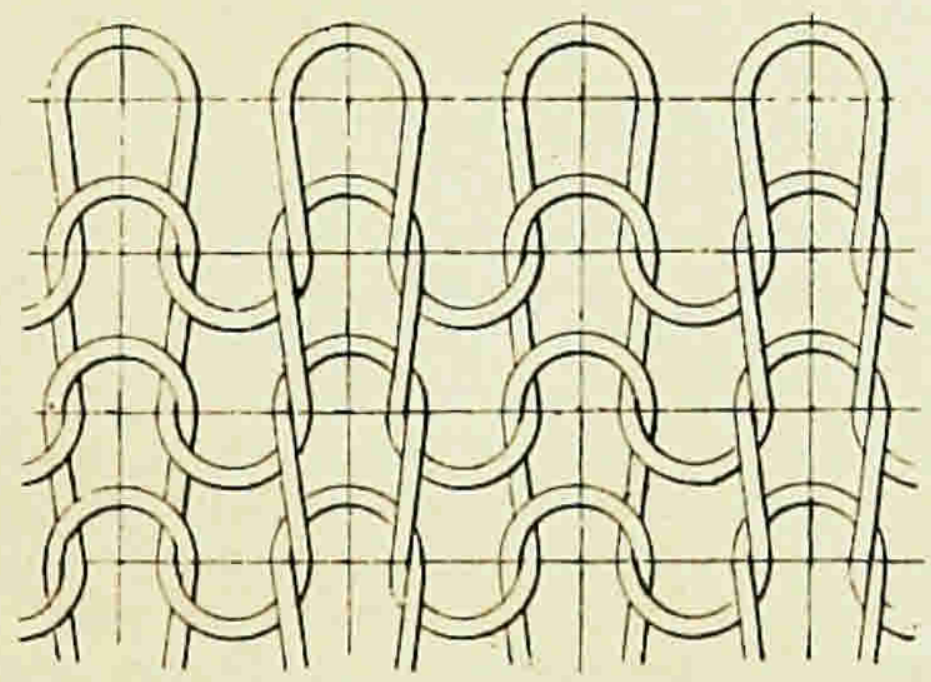

in which the arrangement of the needles is $\mathrm{I} / \mathrm{I}$, the fabric being known as I/I rib work. In this simple rib the two sides of the fabric have a similar appearance, each alternate wale of loops lying in opposite directions.

Pearl Knitting (Class "C").--Pearl fabrics, like rib fabrics, have their loops formed in opposite directions, but in this fabric the whole of the loops of one row may lie in one direction, while the loops of the adjoining row may lie in the reverse direction, or 
the loops of any one row mav lie in opposite directions at the will of the operator, or in accordance with the design being made. Two distinct sets of needles are required in some frames to produce this fabric, but on other frames special needles are used that will form

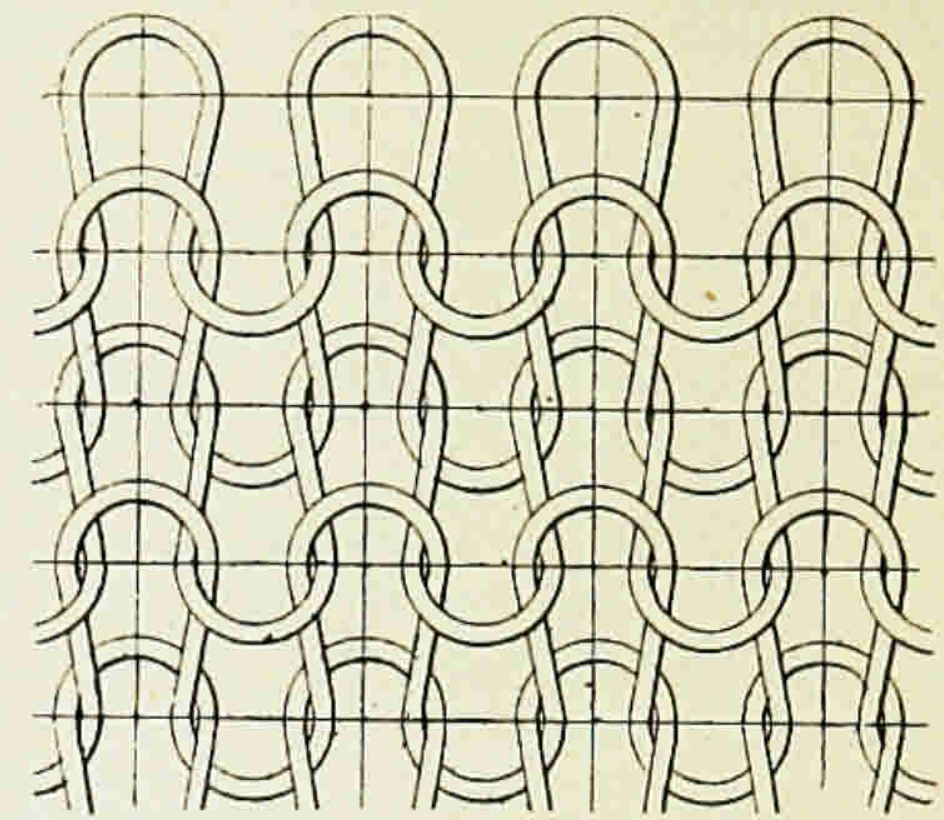

loops in reverse ways as desired. The simplest form of this fabric is known as I/I pearl work, having each alternate row of loops formed in opposite directions; such fabric has a similar appearance on both sides.

One or other of these three principles forms the basis upon which all framework-knitted fabrics are constructed, but owing to the great advance made in the construction of knitting machinery, which was greatly facilitated by the introduction of the latch or self-acting needle as a simpler loop former than the original bearded or spring neledle, these fabrics can be made as flat or selvedged fabrics, and also be made in a circular form of varying widths, and such structural alterations and combinations can be made, that to-day it is possible to produce looped fabrics that are suitable for practically all purposes for which a textile fabric of any kind can be used, and by the methods of their construction the question of production presents no obstacle, for the straightbar frames with bearded needles which follow the principle of the "riginal hand stocking frame are now capable of making all kinds of shaped hosiery and underwear, and at a maximum production, for when making small articles of hosiery as many as 30 separate articles are being made at the same time, while for larger articles the number is proportionate, and this at a maximum speed of 60 rows of loops per minute. The later developments made on the Cotton's Patent type of machine enables many specialities in the way of open work and other fancy designs also to be made.

Plain circular frames with bearded needle circulars can make plain fabrics from a narrow tubular web made on small machines of $2 \frac{1}{4}$ diameter, which is used for the cutting out of dolls' socks, to the high-class tubular fabrics made on frames about $9 \mathrm{ft}$. in diameter, and containing over 9,000 needles, making a fabric of 
double width from which hygienic sheets and bed-coverings can be made. These machines have also been adapted for the making of many specialities, but at the present time the greater varieties of circular fabrics are made on what are technically known as "circular machines," which work with the latch needle, and are capable of using a large number of threads, which gives them a great scope for the production of plain and other fabrics where a variety of stitch and design is required. As an example, a machine making a tubular plain fabric of a coarse (or 12 gauge) type, of I I inches diameter, and working from six threads, makes a 24 -inch fabric at a production of 420 courses per minute. This, on the basis of 14 courses per inch, gives a production of 30 inches of fabric per minute, or 500 yards per day, while finer fabrics (say 30 gauge) are made on 20 -inch machines, using 12 threads, at the rate of 540 courses per minute, and this, with 32 courses per inch, gives a production of 17 inches per minute or about 300 yards per day. On machines having two sets of needles and producing rib fabrics, a coarse machine making a $2 / 2$ fabric for Swiss ribbed vests, such a machine of $\mathrm{I} 2$ inches in diameter, using eight threads, will produce from 50 inches of fabric per minute, the speed being 56 revolutions, knitting 448 rows of fabric per minute. Another similar machine for ribbed underwear, 24 inches in diameter, using 16 threads, makes 480 rows of fabric per minute, the needles in the machine being $\mathrm{I}, 824$; this equals the making of 875,520 finished loops per minute, there being 24 rows to the inch, 20 inches of fabric per minute, or 600 yards per day is an estimated production. The latest development of circular machines is the automatic circular knitting machine for the making of tubular fabrics, and with a capability of making special heels and toes, so that practically a complete stocking can be made on the one machine, and at a production that is scarcely less than marvellous, as a special machine of only $3 \frac{1}{2}$ inches diameter, containing 220 needles and using two threads when making circular fabric, knits at 300 revolutions per minute, giving a production of 132,000 single loops, or 18 inches of fabric per minute, equalling $7 \frac{1}{2} \mathrm{ft}$. every five minutes, and when the heels and toes are made the production of hose equals five dozen pairs per day, and an operator can attend a number of machines. Even finer machines than this are built, having 260 needles in $3 \frac{1}{2}$ inches diameter, or nearly 24 needles per inch, while small machines of 2 inches diameter have 124 needles.

The flat knitting machines, as usually constructed with two sets of latch needles, must be given the first place as the most capable of all the machines making knitted fabric, for not only can circular and flat fabrics be made, but both can be shaped as required, whilst such an arrangement of needles makes the machine specially adapted for all kinds of ribs, including fancy ribs and shog ribs, as well as plain fabrics.

In order to show at a glance the principal effects that can be produced during the mechanical formation of looped fabrics on one or other of these various kinds of machines, I have prepared 
the following table, but it must be noted that though the three primary stitches can be constructed as either flat or circular fabrics, many of the effects here tabulated can only be made in one or more of these stitches, while there are others that may be made circular or as flat fabrics only, while others may be both.

\section{FRAME-WORK KNITTING TABLE. \\ Three Primary Stitches?}

The Plain Stitch (A). The Rib Stitch (B.) The Pearl Stitch (C).

DIVISION OF FABRIC FORMATION.

(a). Effects produced by Thread manipulation.

$\begin{array}{lll}\text { (b). } & \text { Do. } & \text { Accumulation of loops. } \\ \text { (c). } & \text { Do. } & \text { Discarding of loops. } \\ \text { (d). } & \text { Do. } & \text { Shifting of loops. }\end{array}$

SUB-DIVISIONS OF $(a)$.

\section{Principles of Construction.}

I. Changing of threads at any row of loops.

2. Using any number of threads during the making of each row of loops.

3. Using two threads side by side in the making of each row of loops.

4. Reversing two threads as used at 3 .

5. Using separate threads for ground or back loops of fabric, and a number of threads for face of fabric as principle 2 .

6. Vertically worked designs on a plain or horizontal striped fabric.

7. Warp thread designs on plain fabric, with plain or horizontal ground.

8. The using of one or two ground threads with special thread laid in at back.

SUB-DIVISION OF $(b)$.

9. Designing on plain self-coloured fabrics by accumulating loops on individual needles during the making of any row of loops.

10. Designing in colours by accumulating loops, and further by shogging the loops sideways.

II. Designing by combination of plain and ribbed fabrics in conjunction with the accumulation of loops.

SUB-DIVISION OF $(c)$.

12. The using of two or more threads during the making of a row of loops and discarding one or other from certain needles,leaving the discarded thread lying as unknitted loop at the back of the fabric.

13. Ditto on two-needle frames, the loose thread being formed into knitted loops by the additional needles.

SUB-DIVISION OF $(d)$.

I4. The transferring of needle loops from one needle on to the adjoining needle, for producing small holes or open-work.

15. The transferring of needle loops for more than one needle, the needle loops being of variable size.

I6. The transferring of loops in rib fabrics, to form designs by diverting the line of the needle wale.

I7. By transferring the sinker loops of a plain fabric on to one or two needles.
Class of Design.

Horizontal stripes.

Vertical stripes, zig-zags, squares, diamonds, and similar designs.

Plain plated work.

Fancy Plated work.

Combination plated.

Designs.

Imitation embroidery, \&c.

Warp and weft work. Check work, \&c.

Backing and fleecy fabrics. Corduroy and Pile fabrics.

Plain tuck work.

Fancy tuck work, and shogged rib fabrics.

Knopp work.

Press-off work.

Jacquard designs.

Knitted lace work.

Orenburg shawl

fabrics.

Top machine work

Pelerine work. 

the

Taking these sub-divisions in the order named, we have first

(1.) Changing of Threads for Horizontal Stripe Effects.-It is by so changing the threads that any row of loops may be constructed from a different thread that horizontal stripes of almost any design can be made. On straight-bar frames this requires a number of thread carriers, each working independently, and each capable of being used at any course or for any number of courses in succession. If each carrier has its own yarn it will readily be seen that the simple changing of such carriers controls the pattern to be made. The making of circular striped fabrics, where the knitting is continuous, presents more difficulty, especially on circular frames of small diameter using only a few threads. Here, changeable thread guides are required, and these have to be manipulated by some pattern mechanism. The latch needle circular machine is more readily adapted for stripe work, because, being built to use a number of threads, the simple arrangement of these determines the pattern, as the rows of knitting are formed spirally. The range of such patterns depends on the number of threads used, and the capabilities of such a machine using so such threads can readily be seen, while the process of knitting, being continuous, the production is very great; as an example, on a circular machine having I,80o needles, and using so threads, 8o rows of loops are made at each revolution of the frame, or a total of 144,000 loops. The speed of such a machine being eight revolutions per minute, we have a production of 640 rows, with $1,152,000$ loops per minute. A machine making a fine fabric, having some 20 rows or courses of loops per inch, thus gives a production of 32 inches of such fabric each working minute, while the fabric itself, when finished, would be about 20 inches, double width. Such a machine, with a maximum allowance for stoppages produces from $75 \mathrm{lbs}$. to roo lbs. weight of fabric per day, while on coarse machines of the same size and construction, the production would have to be counted in tons.

(2.) To produce Vertical Stripes, etc.-A number of threads are used during the making of a row of loops, each thread being laid over only a portion of the needles. Should such threads always be laid over the same needles, there would be no connection between the one and the other, but a connection must be made by overlapping or other means, a special mechanism being used which gives an apparent prefectly vertical join, the threads being joined at the back of the fabric are not visible on the face of the fabric. On straight-bar frames a number of guide bars are used, each bar with a series of thread guides, so controlled as to travel over a varying number of needles at any course. By the use of a number of such bars and guides, each independently controlled by designing mechanism such as dropper jacquards, etc., it will readily be understood that designs as zig-zags, squares, diamonds, and a various combination can be made according to the traverse of the various thread guides. On circular frames only the simpler 
forms of design can be made, and these only by the aid of special mechanism.

(3.) A Plain Plated Fabric is made from two single yarns worked together as one, but when these yarns are laid upon the needles they are so laid that one appears at the front, and the other. at the back of the fabric; thus it becomes plated, and in this way silk and wool, wool and cotton, and other combinations of yarns may be worked together for varying objects, while in plain knitting, the knitting process is the same as in the making of an ordinary fabric. For rib work such fabrics are made by the using of one thread on each set of needles, the loops being formed on each alternately.

(4.) Fancy Plated Fabrics are made by the reversing of the position of the plating threads on bearded-needle circular frames, either by some mechanical means by which the changing of the position of the thread may be instantaneous, while one or more loops only are made, or by the more successful method adopted on sinker frames where the position of the thread is changed by the actual loop former, with such accuracy that a perfect single needle vertical stripe can be produced. Many elaborate designs can be made in this way, and when combined with horizontal stripe work the patterns become more complex. Simple plated designs can also be made on straight-bar frames by a method of changing the thread by the loop formers.

(5.) Combination Colour Designs made by Plating are produced when the two threads are used independently of each other, the ground thread forming a plain or horizontal striped fabric, while a number of face threads are worked in conjunction with same for the making of a design on the face of the fabric. In this way two effects are produced, first, when the threads are worked together in the ordinary way and therefore intermix with each other during the formation of the loops, and, second, when the threads are laid in a fixed position on the needles as in plating, and the one colour is laid at the face of the fabric and the other at the back. In the making of these designs a number of face threads may be laid over the needles at one row of loops, as explained at No. 2, and these threads need no connection, as they are knitted in with the ground thread. Thus designs can be made with any number of threads, each laid by special thread carriers, and these may be controlled by any known patterning mechanism.

(6.) Knitted Imitation Embroidery are effects produced when the face threads as explained at No. 5 are only laid over certain needles at intervals, the face threads thus having no connection. Each thread guide, having its own thread, forms a separate and independent design, which may be vertical or traverse over a fixed number of needles in either direction, thus making vertical, zig-zag, circular, floral, or other designs on a plain or horizontal striped ground.

(7:) Warp and Weft Designs and Check Work are designs also made on a plain or horizontal ground, a separate guide being 
used to each needle, and each guide lays its thread over one or two needles only at each course. Two principles of designs are made; the one having the warp threads always laid over the same needles, but each guide being so constructed that it lays its thread round the needles only at such courses as desired, thus the pattern is produced by a combination of the number of guides used, the threading of the guides, and the selection of them to lay their thread at any course, this latter movement of the guides being controlled by a jacquard or other patterning mechanism. In such designs the patterning threads are laid vertical throughout the fabric, while the ground threads are horizontal. Check work, a more popular method of designing, is made in a similar manner, but varies by the guides being fixed guides for laying the threads round the needles, and having a sideway movement for a given number of needles. These designs are divided into two classes; those made with a single guide bar with a guide to every other needle, thus the patterning threads form a check or draught-board pattern in combination with the ground thread, and the designs produced may be vertical or zig-zag, according to the colour of the thread used, and the sideway movement of the guide bars. The other class of designs are made with two guide bars, each having a guide to every other needle. As each guide bar is under separate control, and is thus capable of moving in opposite directions, diamond and other similar designs can be made in addition to those made by the single guide bar. In both cases the pattern is determined by the method of threading the guides, and the controlling of their sideway movement. It is on this principle that many of the designs are made when making fancy woollen gloves.

(8.) Brushed and Fleecy Fabrics or Backing Fabrics are made in several ways, quite a number being made on the principle of plating. The yarn used for lying at the back of the fabric is such that it may readily felt or be brushed up, and so give to the fabric a cloth-like appearance; but the term "Fleecy Fabric" implies those fabrics in which the face yarn is knitted in the ordinary way, and the special backing yarn is only laid over needles at intervals, thus leaving a long straight thread lying under the needles, which form loops, which may be afterwards brushed up to give the fleecy effect desired, this effect being determined by the particular class of yarn used and the way in which the fleecing threads are laid in on the needles. When two threads only are used, the one as a ground thread knitted in the ordinary way, and the second as a looping or fleecing thread, it will be well understood that the latter will show on the face of the fabric on those needles over which it has been laid, giving the face of the fabric an irregular appearance; this may be avoided by the use of three threads, two ground threads being laid on the needles on the principle of plating, the fleecing thread being only knitted in by the back ground thread, and in this case does not show in connection with the face thread. Variations are made by the way the backing 
threads are laid over and under the needles, and at which course such threads are laid in. A special corduroy fabric is made when such loops are laid always under the same needles, thus forming a vertical row of loops, which are finished in imitation of corduroy. If such loops are cut, then the fabric may be finished as a cut pile fabric. In contra-distinction, other fabrics are made in which the special yarn used is to form the face of the fabric. It is in this way that imitation astrachans, imitation skins, and fancy looped fabrics are made, the speciality in each case being the class of yarn laid in, looped yarns, mohairs, alpacas, and other special yarns being used.

\section{Division "B." The Accumulation of Loops.}

(9.) Designs in One Colour made by the accumulation of loops upon individual needles are technically known as tuck work, such accumulation being caused by certain needles ceasing to knit; thus loops laid upon them during the cessation of knitting causes them to accumulate on the stem of the needle, the whole to be knocked

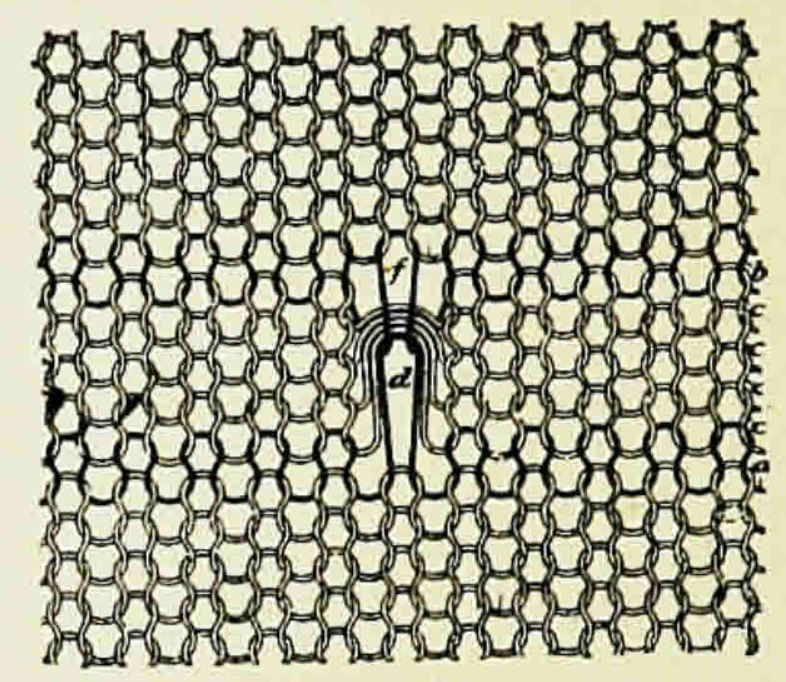

off together the first time such needle again commences to knit. This holding on of the loops causes irregularities in the size of the adjoining finished loops, and so forms prominences on the face of the fabric, which forms the design. In ordinary tuck work loops are accumulated on single needles only, and these may be at varying intervals, and the loops may be retained until, say, five or six loops lie on the needle. It will be well understood that a further quantity of loops would distress the needle and so perhaps prevent it working. The character of the design is according to the choice of needles on which loops shall be accumulated, and to the number of loops so accumulated. When a single thread only is used, making self-colour fabrics, the design depends entirely upon these irregularities as regards their size and position.

(ro.) Tuck Work in Coloured Designs is made when two or more coloured yarns are used; these designs show a combination of 
colour in connection with the irregularity of the surface of the fabric. This principle of design is one of the most popular on looped fabrics, for as the colours used are each laid on the needles separately, those threads that are retained on the needles as unfinished loops ultimately lie at the back of the fabric, being tucked behind the finished loops. On rib frames where two sets of needles are used, loops may be accumulated on either or both of the sets of needles, and it is according to the order of the tucking that standard ribbed fabrics are made. On flat knitting machines or other machines where one or other of the sets of needles have a sideway movement, the loops of the one set can cross the loops of the other set at any desired course, and so form

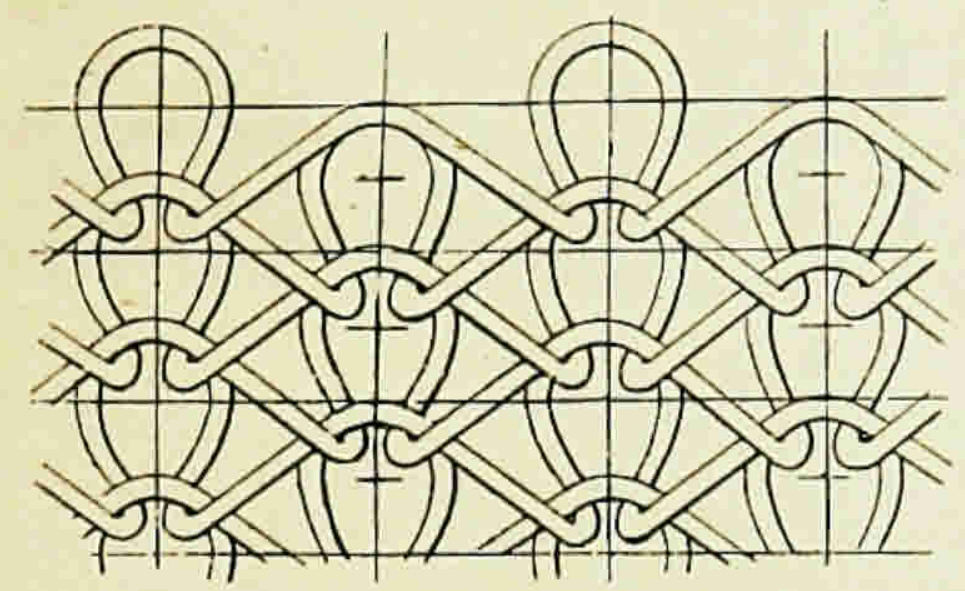

the well-known shogged rib fabric. It is by the arrangement of the needles, so that when shogging, some needles of the one bed cross the needles of the opposite bed, while other needles do not cross other needles, that the fancy shogged fabrics now so largely used in the making of suitable fabrics for ladies' golf jerseys, jackets, coats, and many other garments are made.

(i1.) Knopp Work Designs.-A variation of tuck work known as "Knopp Work" is made on machines with two sets of needles, such machines having a jacquard to control the knitting or nonknitting of any individual needle or needles; thus any needle of one or other, or both sets of needles, may accumulate loops for tucking while other needles may be taken entirely out of knitting action, leaving other needles to knit in the usual way. By this combination of movements, certain needles may knit a number of sectional rows of loops of the plain stitch, while other needles are out of action, this being followed by rib knitting by bringing into action the second set of needles, thus causing the sectional rows of plain fabric to form themselves into small elevated rolls or knopps, and it is the position of these knopps and the varying of such positions controlled by the jacquard that form the principle of this class of design. 


\section{Division "C." The Discarding of Loops.}

(12.) Press-off Work.-Fabrics are made in the plain stitch in which loops are accumulated on the needles, but instead of being retained on same, they are cast off, and lie as loose loops at the back of the fabric. It is in this way that coloured designs can be made, as at any row of loops the particular thread used can be knitted on any predetermined needles, and cast off at others, while at the next row a second coloured thread may be used to be knitted on any predetermined needles, and cast off at others, while at the next row a second coloured thread may be used to be knitted only on those needles where the loops were cast off at the previous

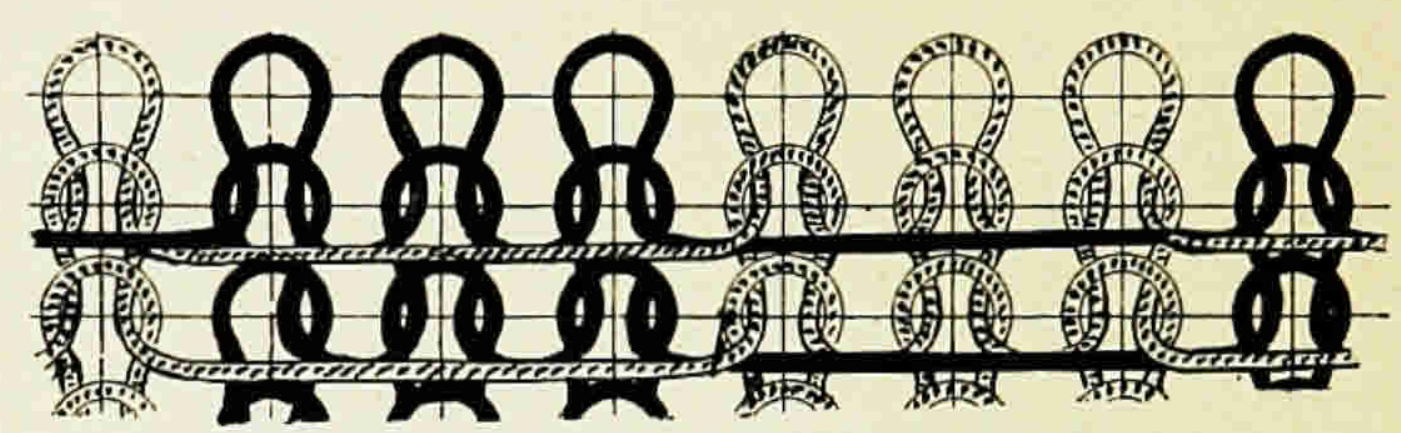

row, so completing a row or course of perfectly shaped loops varying in colour. In all cases the connecting thread from the loop of one colour to the next loop of the same colour lies as a loose thread at the back of the fabric, and so does not in any way cause an irregularity of the knitted loop, so that in such designs the appearance at the face of the fabric is of a regular formation.

(13.) Jacquard Designs.-These designs are made on frames having two sets of needles, the one set being used for forming the designs on the principle of press-off work, while the second set is used to knit up the long loops, which would otherwise lie at the back of the fabric. The needles, being actuated by jacquard mechanism, are selected at each course according to the colour of thread that is being laid, so making designs showing a pattern on the face of the fabric, while the back of the fabric also has knitted loops showing an irregular horizontal stripe according to the way the threads are laid.

\section{Division " D." The Shifting of Loops.}

(14.) Lace Work.-To shift a finished loop from one needle to another has several effects on the fabric, for when a loop is so removed, it must be put upon an adjoining needle to prevent the previously made loops from drawing through each other; therefore the empty needle causes an opening in the fabric at the one needle, and a double loop on the next, the opening being caused by reason of the needle being unable to form a new loop until after two threads have been laid over it. Should knitting continue on the needle, the opening assumes a pure hole, but if each new loop, as 
formed on the needle, should be shifted, the openwork is continued vertically, and as the double loops may be laid on the needle on either side of the opening, so various effects are obtained; thus in designing there are several principles that govern each particular design, namely, the selection of the loops to be shifted, the direction which they shall be moved, and at which courses the shifting

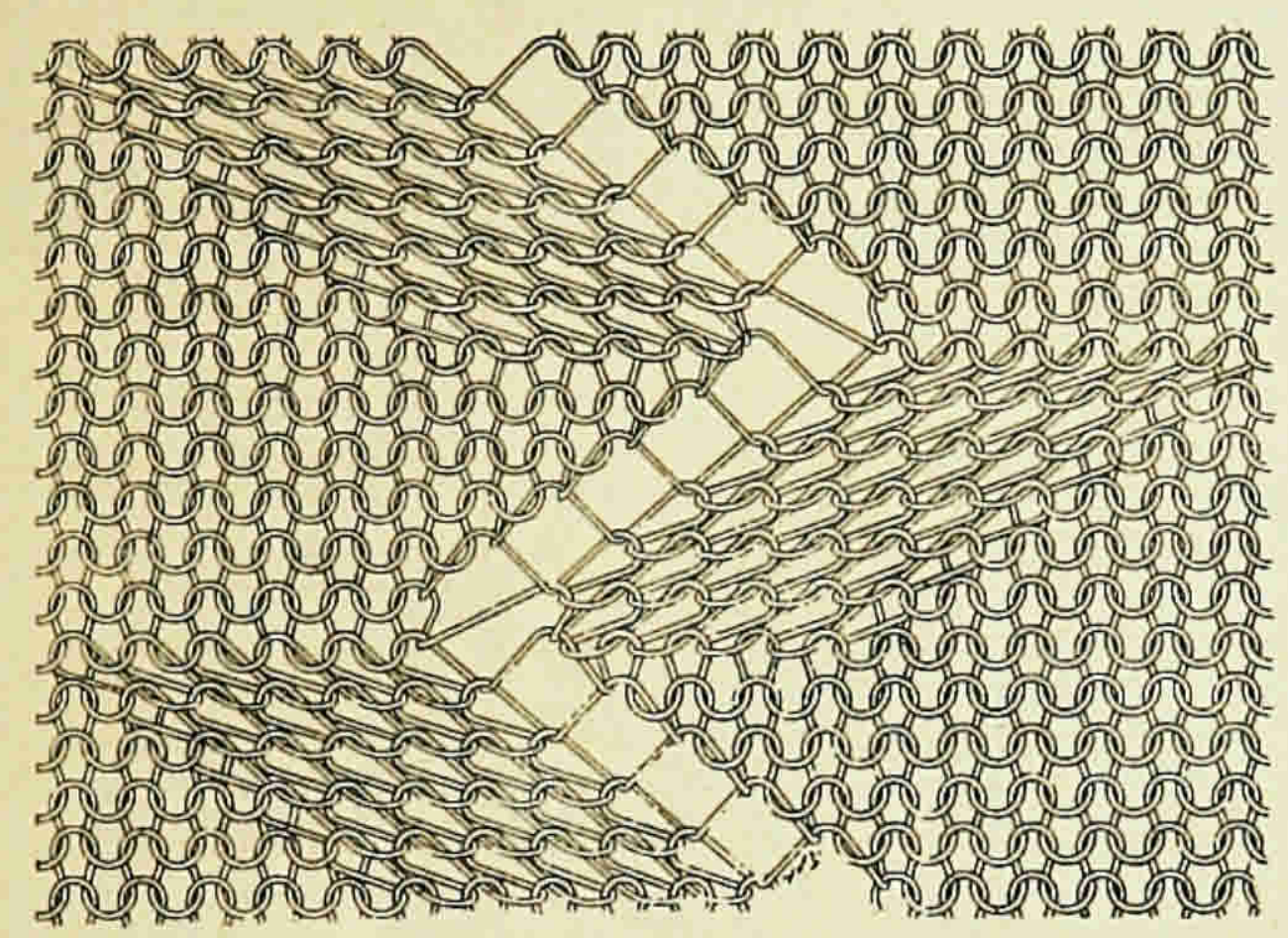

of the loops shall take place. It is in the manufacture of ladies' and children's fine hosiery and underwear that this lace stitch is so popular.

(15.) The Orenburg Stitch.-In making this stitch so popular in that class of shawls, falls, etc., known as "Orenburgs," the principle of shifting the loops is the same as that for the making of the lace stitch, but the loops of this fabric are constructed so that certain rows of loops may have much longer loops, thus enabling the removed loops to be shifted two, three, or more needles' distance on either side, so making much larger openings, while a drawn effect to the threads assists in the formation of design.

(16.) Top Machine Work.-In making this class of work on rib frames with two sets of needles, loops are removed from one needle to another on either one set or the other of the needles. The more popular method of designing is when the loops of one set of needles only are removed, as by this method the shifting loops cross and re-cross the loops formed on the second set of needles, which gives a two-fold effect; first, by the removing of the loops, the needle wales on the one side of the fabric are diverted by being connected to the adjoining needle wales, thus enabling a variety of designs to be made in accordance with the way the loops are shifted, and, 
again, when such loops have been shifted the loops formed by the second set of needles are at such positions shown at the front of the fabric, and when colours are used a combined effect with the needle design is obtained.

(17.) Pelerine Work.-This is a special shawl fabric, in which designs are produced by the shifting of the sinker loop, or the loop that is formed between the needle loops, and which lies in reverse position to the needle loop. To form the design these sinker loops are brought up and placed on to the needles on either side or over both of such needles. In either case this has the effect of drawing together the needle loops and forming them into elevations, while where the sinker loops remain, openings are formed, and as the machines on which these fabrics are made are

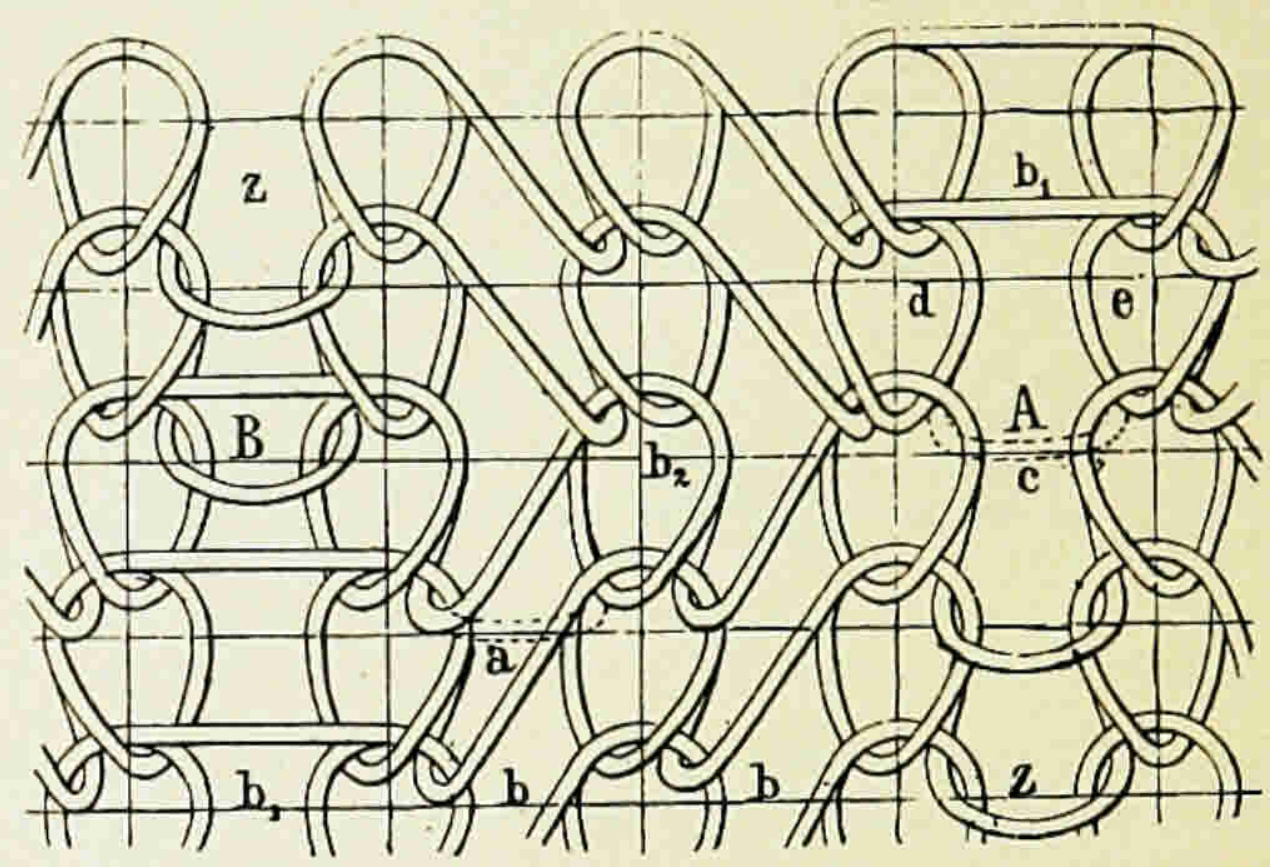

constructed to make varying lengths of loops at any course, so the size of the elevations and openings are regulated, while the designs themselves are due to the order in which the sinker loops are removed.

Besides the various fabrics described under the foregoing headings, there are many others that would be difficult to classify, and mav be better termed "specialities." Among these are included the special "Twist Fabric," practically a plain knitted fabric, in which the needle loops are twisted in the process of making; the "puttee knitted cloths," which are circular plain knit, having an additional weft thread laid in straight without looping by the same intersecting the knitted weft; " non-elastic fabrics," having a set of straight or warp threads crossed with a set of straight weft threads, which do not intersect each other, but are connected into the fabric during the making of the ordinary plain knitted stitch. Of recent introduction we have such fabrics as the "Inter-lock," which is a knitted fabric of close and firm texture, and consists of two 
interlocked rib webs with crossed sinker wales, the ribs of each face of the one web being disposed in the spaces between the ribs of the face of the other web, and to produce which circular machines have two sets of needles in which the odd needles of one set and the even needles of the other set knit alternate with the even needles of the first set and the odd needles of the second set. The "Bi-knit" fabric is a special knitted fabric practically composed of two circular fabrics which are independent of each other, but which are united by the yarn of the one engaging or being looped in with the other fabric at intervals. It is made normally by one set of needles knitting at one feeder, and the other set of needles knitting at the next feeder, but at intervals needles of both sets knit from the same yarn and thus connect the fabrics at these points.

\section{Warp KNitted Fabrics.}

Looped fabrics, as made from warp threads, are more varied than framework knitted or weft fabrics, as the principle of a thread to each needle enables a far greater manipulation of the threads in addition to the accumulating, transferring, etc., of the loops as in framework knitted fabrics. This being so, it is beyond the scope of this paper to deal with the construction of this class of fabrics, and I must therefore be content to briefly outline some of the main principles upon which warp loop fabrics can be constructed, leaving the details for the future.

In warp fabrics there are two main factors that govern their construction, viz., the machine and the character of the fabric. The former is equally as important as the latter, for warp machines are very varied in principle and in the detail of their construction, being built to work both the bearded and latch needles, and these with one or two sets of needles, while the number of thread guides used from one, say, to eight, enables a varying number of threads to be used in the formation of one row of loops, and, in addition to the accumulation, shifting and other manipulation of them. Briefly summarised, we have the-

Flat warp looms with one set of horizontal bearded needles,

Fast warp looms with one set of vertical bearded needles, Jacquard warp looms with two sets of bearded needles,

Latch needle warp looms with horizontal needles,

Latch needle warp looms with vertical needles,

Latch needle warp looms with two sets of vertical needles, each with a varying number of guide bars and complement of appliances for varying the class of fabric produced.

\section{WARP FABRICS}

are mainly divided into two distinct classes, close warp and open warp fabrics, the former including all fabrics in which the threads have a sideway connection at each row of loops, and the latter those 
which only have such connections at intervals. These may be classified according to the following :-

Warp Knitting: Division of Fabric Formation.

Close Fabrics (D). Open Fabrics (E).

DIVISION OF (D).
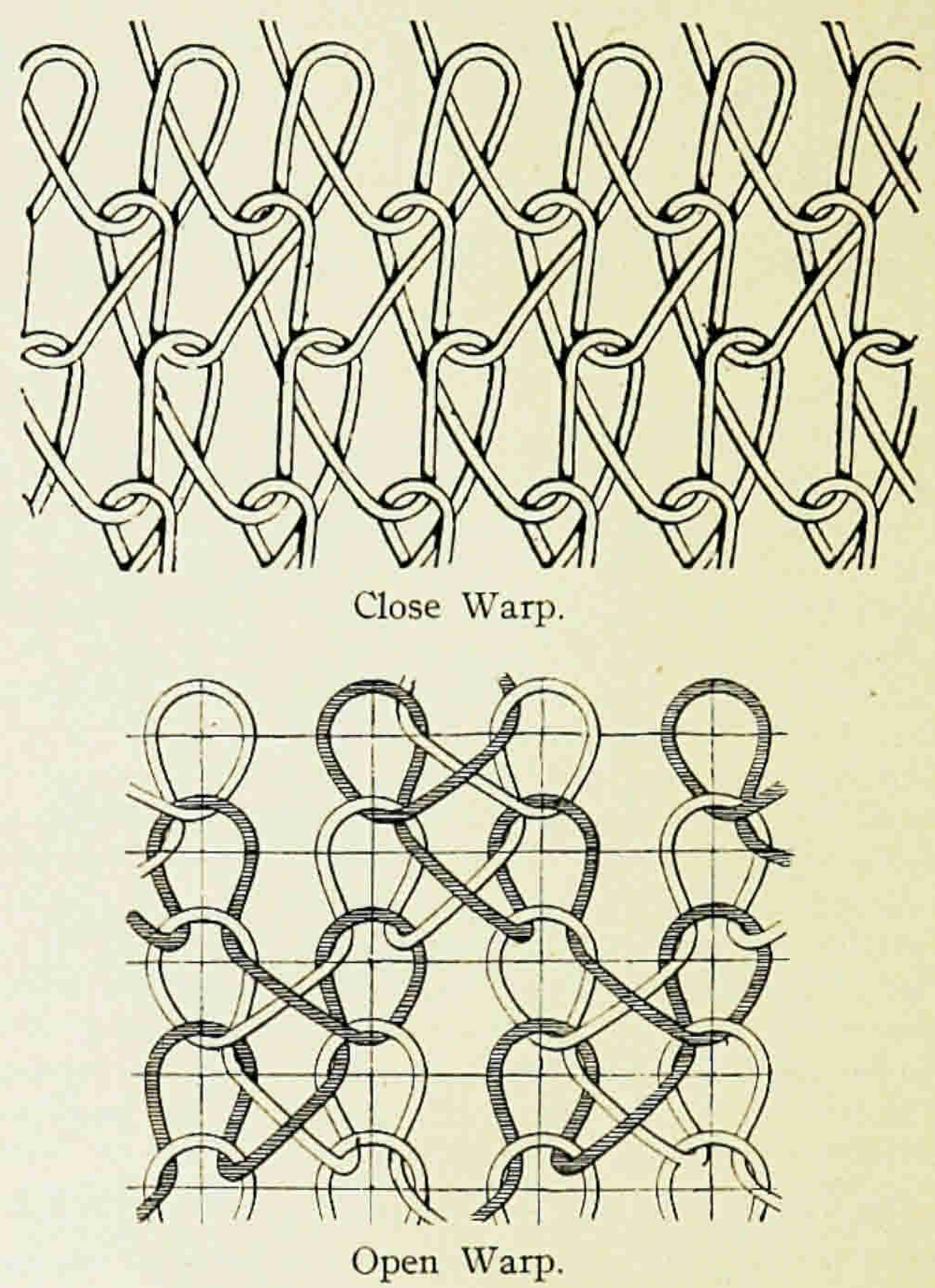

I8. Close fabrics made with one set of needles and one guide bar.

19. Close fabrics made with one set of needles and two or more guide bars.

20. Close fabrics made with two sets of needles and one guide bar.

2I. Close fabrics made with two sets of needles and two or more guide bars.

22. Close fabrics with super-imposed designs.

23. Close fabrics or crêpe fabrics.

24. Plain warp net fabrics.

$$
\text { DIVISION OF (E). }
$$

25. Jacquard net fabrics.

26. Lace net fabrics. 
Under class 18 are made such fabrics as plain or Denbigh, vertical stripes, vandykes, cords, Berlins, and similar fabrics, while under classes I9 to 23 are made double Denbigh, double vandyke, and diamond fabrics, warp knitted cloths, fleecy fabrics, plush and pile fabrics, imitation lamb skins and seal skin fabrics, plated fabrics, traverse warp or Milanese cloth, scarf and shawl fabrics, trimmings, fringes, etc.

Under class 24 are made plain nets, pillow nets, and fancy tuck nets; under class 25 all the variety of nets produced by the Jacquarding of threads and needles, while class 26 includes the special curtain nets which form the missing link between the looped and twist fabrics, some of the looped productions being only distinguished from the twist varieties by experts, these including both the bar nets and the string or picker lace warp fabrics.

This vague introduction on warp looped fabrics, as previously stated, is only intended to convey the idea of the vast capabilities that this class of looping presents, and which has been so studied by our Continental competitors as to place us in a second position as regards their manufacture, and here especially must science, art, and manufacture work hand in hand if we are to hope to regain this lost branch of the knitting industry, for without designs results are hopeless, and it is on this point that our competitors succeed, and I cannot conclude without referring to the oft-repeated query: "Why do our manufacturers neglect this, the most interesting and, no doubt, most profitable branch of the industry?"

In concluding, I have endeavoured to show that looped fabrics are so varied and so capable of variation that they have in special cases become a strong rival to both twisted and woven fabrics as regards their structure, while as a matter of production both are left hopelessly behind. I have also attempted to show that looped fabrics can be made that are suitable for any purpose for which any textile fabric may be applicable, as stated in my opening remarks. If manufacturers of such fabrics desire to increase the adaptabilities of looped fabrics, surely they have sufficient scope before them. The question in the past has been one of cheapness, which has brought the price of productions of ordinary plain fabrics to the rock bottom, and manufacturers should now turn their attention to the improvement of the industry by widening the field of demand. Before this can be successfully done, however, the old "rule of thumb" systems that have been connected with the trade in the past must be cleaned from the slate, and the study of science and art in the manufacture of looped fabrics must take their place. How often are difficulties brought about by a lack of the knowledge of the true nature of the raw materials used, the same yarn being used for making garments of different textures in which the strain of the thread in the one case is such that proves disaster to the results desired. This will readily be understood, for when loops are accumulated, strain must be put upon the threads, and also in some cases of the shifting of the loops, but even strength must be accompanied by softness in most cases, and here it is where 
science must be brought to the assistance of the industry. Art, too, must be studied, for without doubt we are behind our competitors in the application of colour and design, and to succeed we must strive for a premier position, and not be content to play second fiddle. The inclusion of the manufacture of outer garments in this industry needs a much closer study of the human figure if style is to play any important part in progress in this direction, for in outer garments the theory of the hosiery and underwear departments that "if a garment is too long it may be turned up" will not be permissible, and the garment which will not fit the body will be at fault, and not the body for failing to fit the garment.

Note.-In order to demonstrate more fully the formation of looped fabrics, I am showing over Soo separate samples of such fabrics, the same being classified and numbered under the subdivisions given.

A. B. C., Nos. I to $I \pi$, show the different methods of loop formation in plain, rib, and pearl fabrics, and D. E., Nos. 18 to 26 , show those of open and close warp formation.

There was no discussion on the paper, but Mr. C. J. Wilson (Hawick) remarked that, although he knew nothing about hosiery manufacturing, it seemed that they, in Hawick, were behind in the introduction of the looms and frames which had been so well described. He hoped that those engaged in this trade locally would not neglect the opportunity of consulting with Mr. Quilter and perhaps introducing some of the frames to enlarge the scope of their business.

This concluded the session and the delegates adjourned to the Town Hall, where they were entertained to a luncheon.

\section{Textile Machinery Exhibition.}

In the afternoon Lord Rotherham opened the first Congress exhibition of textile machinery and appliances in the Drill Hall.

His Lordship said that, after looking round at most of the exhibits, he could say that it gave him very real pleasure to fulfil the request that had been made to him to declare the exhibition open. He hoped that the exhibition, which he now declared to be open, would amply reward those exhibitors who had sent their machines to Hawick by the receipt of orders from firms or individuals connected with different trades requiring those machines. From what he had been told, he understood that there had been no difficulty whaterer in getting machine makers to send exhibits. Indeed, he believed a place very much larger could have been filled had there been such a place. Some very well-known machine-making firms were represented, and some of those present knew from experience the excellent quality of machinery they produced. It 
was not always easy to get machine makers to send exhibits. He had come from Newcastle that morning, and our Consul at Antwerp had asked him to mention that they were very anxious, in connection with an exhibition which was to be opened next year at Ghent, to have a large number of English machine makers sending their exhibits to that exhibition. That exhibition was, to some extent, under the patronage of the English Government, and our Consul told him that he thought that any machine makers sending their exhibits there would be amply rewarded by the sales they would be able to make in consequence.

\section{Social Functions.}

Subsequently the delegates viewed the exhibition of the work of students attending the technical institutes in several of the textile centres of the United Kingdom. The exhibition was in Buccleuch Technical Institute, and the exhibits were most varied and interesting. The remainder of the afternoon was occupied with visits to local tweed factories, hosiery factories, dyeing and cleaning works, and the Hawick Electricity Works. In the evening Provost Melrose and the Magistrates and Town Council of Hawick gave a reception in the Town Hall, which proved to be most enjoyable. 